\title{
Sarcoma obstructing right ventricular cavity: clinical, echocardiographic, haemodynamic and angiographic features
}

\author{
Alasdair D. Malcolm \\ M.R.C.P. (U.K.)
}

\author{
Man FaI SHIU \\ M.R.C.P. (U.K.)
}

\author{
B. STEPHEN JENKINS \\ M.R.C.P.
}

Cardiac Department, St Thomas's Hospital, London SE1 7EH

\begin{abstract}
Summary
Right atrial hypertension and pericardial effusion developed 2 years after mastectomy for fibrosarcoma. Clinical and echocardiographic features suggested right ventricular tumour. At catheterization the right ventricular cavity was almost obliterated, with an infundibular gradient of $13 \mathrm{mmHg}$, and biopsy of the mass was attempted. Post-mortem revealed extensive infiltrating and intracavitary right ventricular fibrosarcoma without extracardiac tumour.
\end{abstract}

\section{Introduction}

Yater, writing in 1931 on sarcoma of the heart, noted that it was remarkable how the neoplasm could become so extensive and the heart continue to function. The case now reported reinforces this point and demonstrates a number of clinical features of an infiltrative right ventricular tumour (Yater, 1931; Whorton, 1949; Harvey, 1968).

Constitutional symptoms, which are so common in atrial myxomas, are usually absent in tumours of the right ventricle (Goodwin, 1968); the most striking clinical sign in a high right atrial pressure (Whorton, 1949; Goodwin, 1968; Harvey, 1968). Non-specific ECG features develop when tumours invade the ventricular wall (Goodwin, 1968; Roberts, Bodey and Wertlake, 1968). Intracardiac tumours can often be detected echocardiographically but with right ventricular tumours the diagnosis is readily missed on M-mode studies (Ports, Schiller and Strunk, 1977). Angiocardiography is of key importance in excluding right atrial myxoma in any patient with unexplained right-sided heart failure (Goodwin, 1968) and with right atrial injection will also delineate the intracavitary irregularities of an encroaching tumour of the ventricular wall, as well

Correspondence to: Alasdair D. Malcolm, M.R.C.P. (U.K.), Airedale General Hospital, Steeton, Keighley, West Yorkshire BD20 6TD. as providing direct evidence of the pericardial effusion which is not infrequent with cardiac sarcomas (Whorton, 1949; Prichard, 1951).

\section{Case report}

A 45-year-old woman was transferred to $\mathrm{St}$ Thomas's Hospital with a 4-month history of general tiredness and increasing exertional dyspnoea, without orthopnoea, chest pain or haemoptysis. Ankle swelling had developed during the last 2 weeks. A left mastectomy had been performed 2 years earlier and histology of the specimen showed fibrosarcoma. There had never been any evidence of local recurrence of the tumour.

During the current illness she had been admitted initially to another hospital where elevation of the jugular venous pressure was noted and a tentative diagnosis of pulmonary embolism made. Four days before transfer anticoagulation was initiated with heparin, and oral warfarin was also commenced. Isotope lung scans and contrast leg phlebograms were normal.

On examination, the patient looked exhausted and immediately became dyspnoeic on the slightest movement. She was not anaemic, cyanosed or clubbed. There was no lymphadenopathy and the scar of the previous left mastectomy was well healed. Peripheral pulses were of small volume and the heart rate was $120 / \mathrm{min}$ and regular. Jugular venous pressure was elevated more than $15 \mathrm{~cm}$ above the sternal angle with a triple waveform and no apparent inspiratory filling or prominent descents. Arterial systolic pressure was $95 \mathrm{mmHg}$ by palpation and a left parasternal impulse was present. On auscultation the first heart sound was normal and the second sound single, with a faint third sound which did not vary with respiration. There were signs of bilateral small pleural effusions but no crepitations above the effusions. Slight ankle oedema was present and the calves were normal. 
The electrocardiogram was bizarre with sinus tachycardia, extremely low voltage complexes in the standard leads, mean frontal QRS vector at $-90^{\circ}$, broad slurred dominant $Q$ waves in leads II, III and aVF, and a dominant broad $R$ wave with $T$ wave inversion in leads V1 to V4. Chest X-ray showed a globular cardiac silhouette with a cardiothoracic ratio of 15:28 and bilateral basal effusions. There were no notable haematological or biochemical abnormalities and the ESR was $4 \mathrm{~mm} /$ hour (Westergren). Echocardiogram (Fig. 1) revealed normal echoes from the aortic and mitral valves, and the presence of pericardial fluid. The interventricular septum was abnormally thick $(2.0 \mathrm{~cm})$, and there were bands of dense abnormal echoes in the right ventricular cavity and outflow tract. Tricuspid valve echoes could not be distinguished.

Cardiac catheterization (Fig. 2) established that the patient had a low pulmonary arterial pressure (phasic 13/4, mean $6 \mathrm{mmHg}$ ) with a considerable gradient between the body of the right ventricle $(26 / 14 \mathrm{mmHg})$ and the pulmonary artery and a high right ventricular end-diastolic pressure, as well as very high right atrial pressures (a wave 19 , v wave $18, x$ trough 12 , y trough 16 , mean $17 \mathrm{mmHg}$ ). The pressure in the left atrium was recorded through a Brockenbrough trans-septal needle and found to be very low (mean $1 \mathrm{mmHg}$ ). Right atrial angiogram showed a dilated right atrium with separation from the edge of the cardiac silhouette characteristic of pericardial effusion, and the contrast material then passed to the pulmonary artery through a short irregular channel (Fíg. 3) in an otherwise completely obliterated right ventricular cavity. Biopsy of the right ventricular mass was attempted with a cardiac bioptome (modified Olympus fibreoptic bronchoscopic biopsy forceps, Keymed Ltd) passed through a long sheath positioned with its tip just through the tricuspid valve, but no tissue was obtained with 3 attempts.

After catherization the patient remained in a low cardiac output state and died $24 \mathrm{hr}$ later. At postmortem there was a small amount of blood in the pericardial space but the pericardium was not under tension. The right ventricular wall was thickened and entirely composed of tumour tissue which extended into and almost filled the ventricular cavity from the tricuspid valve to the infundibulum. The valves were normal, as also were the pulmonary arteries and lungs. No extra-cardiac tumour tissue was found. Histology confirmed that the heart was extensively infiltrated with poorly differentiated fibrosarcoma.

\section{Discussion}

This patient's right ventricular sarcoma was probably a secondary tumour from the left breast fibrosarcoma removed 2 years earlier. Cardiac tumours are rare (Yater, 1931; Whorton, 1949; Prichard, 1951; Goodwin, 1968; Harvey, 1968). Metastatic tumours of the heart occur with approxio mately 20-40 times the frequency of primar growths (Prichard, 1951). Carcinomatous metastases are more common than sarcomatous (Yater 1931), but the pattern of diffuse infiltration and replacement of the myocardium, sometimes with

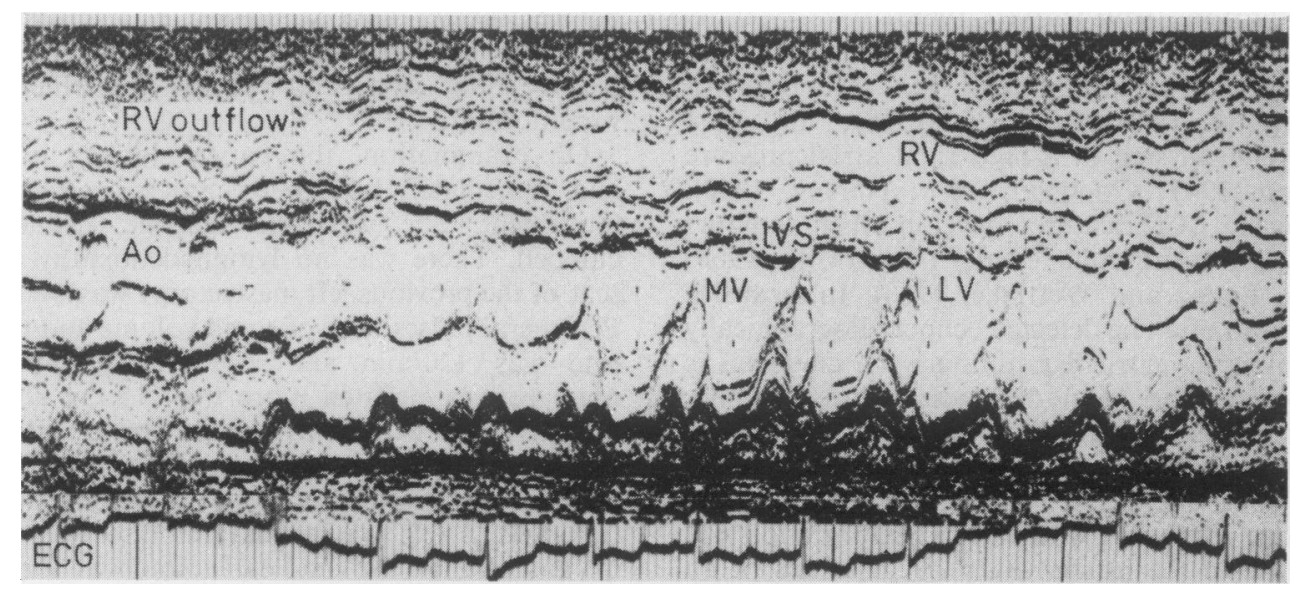

FIG. 1. Echocardiogram with standard sweep recording from aortic root to apex of the heart. The aortic (Ao) and mitral (MV) valves and left ventricular (LV) cavity size are normal. The interventricular septum (IVS) is thickened and bands of abnormal echoes extend from the right ventricular cavity (RV) into the infundibulum (RV outflow). A pericardial effusion is present. Calibration marks are $1 \mathrm{~cm}$ and $0.5 \mathrm{sec}$ apart and a reference electrocardiogram (ECG) is shown at the bottom. 


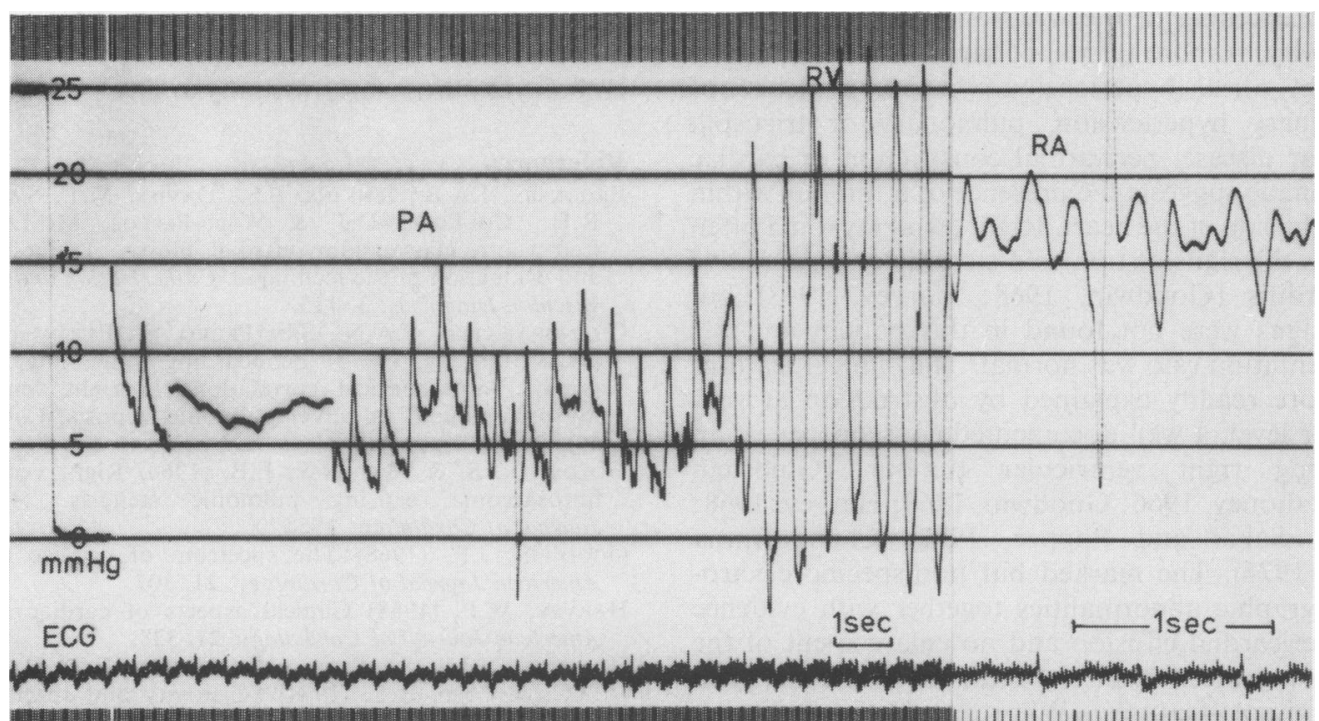

Fig. 2. Pressure tracings on withdrawal from pulmonary artery (PA), through right ventricle (RV), to right atrium (RA) showing the low pulmonary arterial pressure, higher pressures in the right ventricular cavity, and high right atrial pressures. There are no features of tricuspid stenosis, tricuspid regurgitation or pericardial effusion with tamponade.
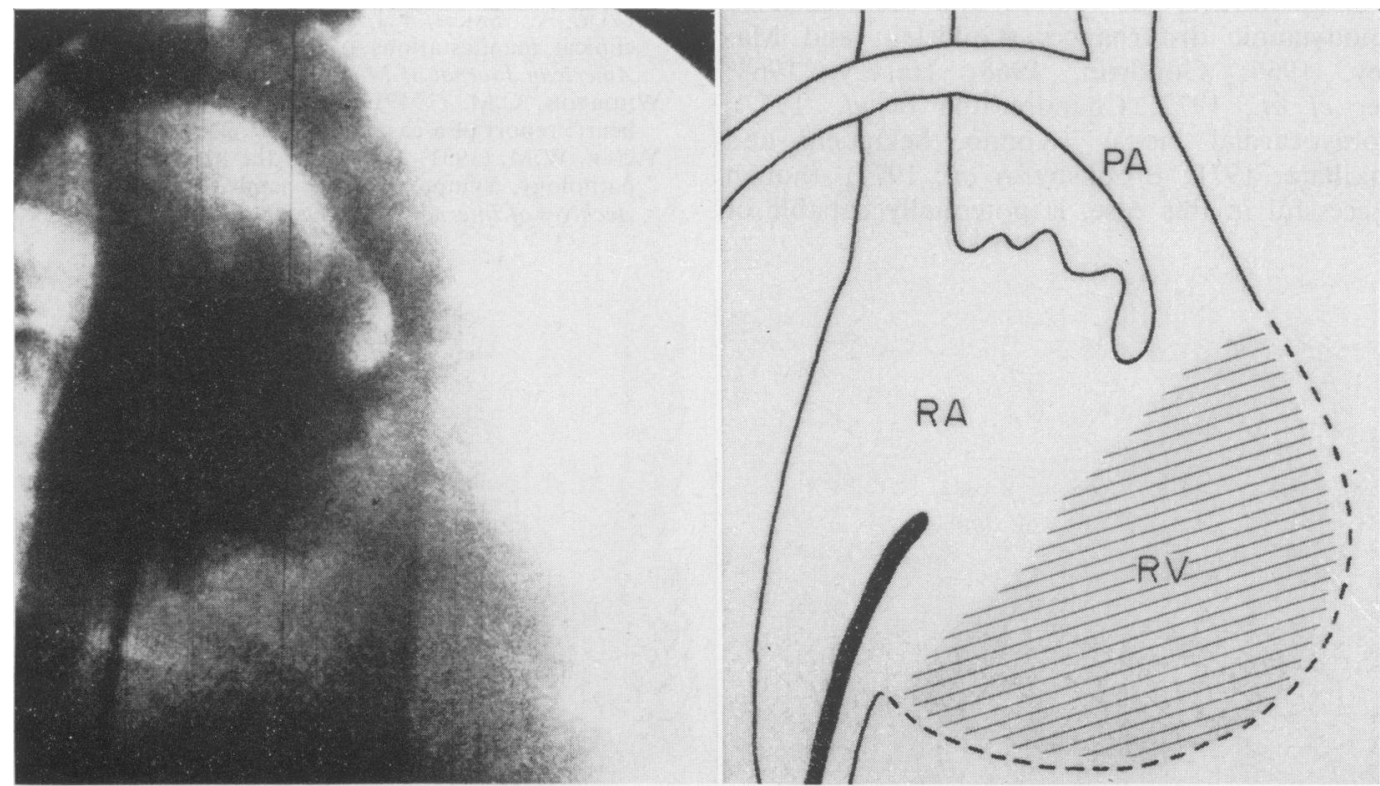

FIG. 3. Single frame from ciné-angiocardiogram in anterior projection, following right atrial injection, showing contrast passing from right atrium (RA) to pulmonary artery (PA) through a short irregular channel above the body of the right ventricle (RV) which is almost obliterated by encroaching tumour. 
great thickening of the walls and encroachment on the cavity, is more typical of sarcoma (Yater, 1931).

Right atrial hypertension without evidence of pulmonary hypertension, pulmonary or tricuspid valvular disease, pericardial constriction or cardiac tamponade suggests the presence of a tumour within the right side of the heart. Right atrial myxoma often mimics the signs of tricuspid stenosis or constrictive pericarditis (Goodwin, 1968; Harvey, 1968) but such signs were not found in this patient and the sedimentation rate was normal. The clinical features are more readily explained by obstruction at ventricular level, a well documented consequence of an enlarging right ventricular tumour (Goldstein and Mahoney, 1966; Goodwin, 1968; Harvey, 1968; Selzer, Sakai and Popper, 1972; Chandraratna et al., 1977). The marked but non-specific electrocardiographic abnormalities together with evidence of a pericardial effusion and no enlargement of the pulmonary arteries on the chest X-ray are expected concomitant features (Whorton, 1949; Prichard, 1951; Goodwin, 1968; Harvey, 1968; Roberts et al., 1968). Echocardiography confirmed the presence of pericardial fluid (Horowitz et al., 1974) and the mass of dense echoes from the right side of the heart, although difficult to distinguish from artefact at the time of recording, presumably arose from the intracavitary tumour (Chandraratna et al., 1977; Ports et al., 1977)

Cardiac catheterization with angiocardiography is the definitive investigation to establish the site and size of an intracardiac tumour and the associated haemodynamic disturbances (Goldstein and Mahoney, 1966; Goodwin, 1968; Harvey, 1968; Selzer et al., 1972; Chandraratna et al., 1977). Endomyocardial biopsy (Konno, Sekiguchi and Sakakibara, 1971; Brooksby et al., 1977), though unsuccessful in this case, is potentially capable of securing tissue for histology but caution must be exercised in view of the possibility of tumour embolism, particularly with myxomas.

\section{References}

Brooksby, I.A.B., Jenkins, B.S., Davies, M.J., SWanton, R.H., Coltart, D.J. \& Webb-Peploe, M.M. (1977) Left ventricular endomyocardial biopsy. I: Description and evaluation of the technique. Catherization and Cardiovascular Diagnosis, 3, 115.

Chandraratna, P.A.N., San Pedro, S., Elkins, R.C. \& GraNTHAM, N. (1977) Echocardiographic, angiocardiographic, and surgical correlations in right ventricular myxoma simulating valvar pulmonic stenosis. Circulation 55, 619.

Goldstein, S. \& Mahoney, E.B. (1966) Right ventricular fibrosarcoma causing pulmonic stenosis. American Journal of Cardiology, 17, 570.

Goodwin, J.F. (1968) The spectrum of cardiac tumors. American Journal of Cardiology, 21, 307.

HaRveY, W.P. (1968) Clinical aspects of cardiac tumors. American Journal of Cardiology, 21, 328.

Horowitz, M.S., Schultz, C.S., Stinson, E.B., Harrison, ס D.C. \& POPP, R.L. (1974) Sensitivity and specificity of $\triangle$ echocardiographic diagnosis of pericardial effusion. Circulation, 50, 239.

Konno, S., Sekiguchi, M. \& Sakakibara, S. (1971) Catheter biopsy of the heart. Radiologic Clinics of North America, 9 , 491.

Ports, T.A., Schiller, N.B. \& Strunk, B.L. (1977) Echocardiography of right ventricular tumors. Circulation, 56, 439.

Prichard, R.W. (1951) Tumors of the heart; review of the subject and report of one hundred and fifty cases. Archive of Pathology, 51, 98.

Roberts, W.C., Bodey, G.P. \& Wertlake, P.T. (1968) The heart in acute leukaemia: a study of 420 autopsy cases. American Journal of Cardiology, 21, 388.

Selzer, A., SAKai, F.J. \& Popper, R.W. (1972) Protean clinical manifestations of primary tumors of the heart. American Journal of Medicine, 52, 9.

Whorton, C.M. (1949) Primary malignant tumors of the heart: report of a case. Cancer, $2,245$.

YATER, W.M. (1931) Tumors of the heart and pericardium: pathology, symptomatology and report of nine cases. Archives of Internal Medicine, 48, 627. 